\title{
PULL-OUT TESTS OF A NEW HOOKED STEEL-GFRP COMPOSITE CONNECTOR IN PRECAST CONCRETE SANDWICH PANELS
}

\author{
Dongzhi Guan*, Zhengxing Guo*, Huanzhi Jiang*, Dan Ju* \\ * Southeast University, School of Civil Engineering, China \\ e-mails: gdzh.js@163.com,guozx195608@126.com,704358537@qq.com,1586321886@qq.com
}

\begin{abstract}
A new hooked steel-GFRP composite connector was proposed for precast concrete sandwich panels. The new connector consisted of a steel core and glass fiber-reinforced polymer (GFRP) as outer covering layers processed by injection molding machines. It was intended to connect the inner and outside layers of precast concrete sandwich panels with high structural performance, low thermal conductivity and ease of installation. To investigate the anchoring capacity of the new connector in concrete, pull-out tests were carried out on total 9 test specimens. Experimental results were analysed including pull-out strength, failure pattern, load-slip curve and load-strain curve etc. Results show that all the test specimens fail with the pattern of pulling out of concrete cone. Slippages between the connectors and concrete remain negative when the specimens were damaged. Hook of the connector linking the intersection of reinforcing bars improve the pull-out capacity significantly. The pulling-out capacity of the new connectors increase with the increment of concrete strength grade; and the average pulling-out capacity of the connectors become more than 5 times pulling-out load required by the Chinese code.
\end{abstract}

Keywords: Hooked steel-GFRP composite connector, Precast concrete sandwich wall panels, Pull-out test.

\section{INTRODUCTION}

With the promotion of Construction and Housing Industrialization process, precast structures are increasingly used. As important components in precast structures, energy-saving insures of walls are the key to achieve green building, which have good developing prospects. Nowadays, there are three types of thermal insulation walls, that is internal, external and sandwich thermal insulation walls. Internal thermal insulation walls are not conducive to interior decoration, and easy to be damaged. External thermal insulation walls are weak in fire proofing, and outside plastering concrete layer cannot exist as long as main structures. A sandwich thermal insulation wall consists of an inner and an outside layer with insulation material placed between them, of which connectors makes the wall panels and insulation materials work as a whole. It can function well in load bearing, enclosure and thermal insulation, and also effectively prevent the impact of external environment and interior decoration, thus it has the same lifespan as the main structures. Precast concrete sandwich panels represent future development of energysaving building's exterior thermal insulation wall ${ }^{[1]}$.

The connector serves as a key component connecting concrete panels and insulation layers in sandwich walls, and resisting the shear stress under gravity load and tension or compression under wind load ${ }^{[2]}$. The widely accepted types of connectors precast concrete sandwich walls are made of deformed bars, stainless steel and fiber reinforced plastic (FRP), respectively. Bar truss connectors are cheap with high coefficient of heat conductivity, leading obvious "hot bridge" effect. Moreover, it is highly possible to cause safety hazards with poor corrosion resistance ${ }^{[3]}$. Stainless steel connector can reduce heat loss significantly with very low thermal conductivity coefficient, and durability can be improved, but Stainless steel connectors are very expensive. A fiber reinforced plastic (FRP) connector has high tensile 
strength, corrosion resistance and small thermal insulation coefficient, but its low shear strength (only 5\% to $20 \%$ of tensile strength) will lead to interlayer shear failure at insulated connector between inner and outside layers of precast concrete wall panels ${ }^{[4]}$, reducing the safety.

In this paper, a new hooked steel-GFRP composite connector was developed using high-strength indented wires or ribbed bars as cores and glass fiber-reinforced polymer (GFRP) as outer covering layers as shown in Fig. 1. One end of the new connector was made into a hooked shaped while the other end was straight. It could effectively utilize the high tensile and shear strength of the steel cores and high corrosion resistance of GFRP, eliminating problems of conventional connectors between inside and outside layers. To investigate the anchoring capacity of the new connector in concrete, pull-out tests were carried out on total 9 test specimens. Systematically analysis on test results was conduct including pullout strength, failure pattern, load-slip curve and load-strain curve, etc.

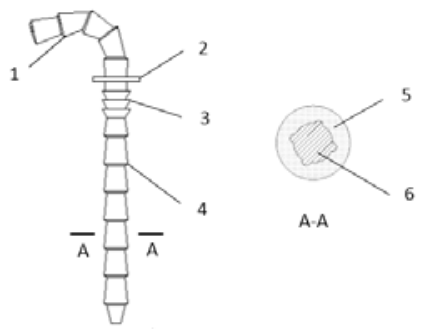

1.Hooked head 2.Locating ring 3. Transition section 4.Inverted cones 5.Glass fiber resin layer 6.Steel core

Figure 1. Example of a figure.

\section{TEST PROGRAM}

\subsection{Specimen design}

Three groups of 9 specimens were test by pulling out. Every group included 3 specimens. Concrete of two strength grade, $\mathrm{C} 25$ and $\mathrm{C} 35$, was used to make specimens. The placement of the new connectors were different, some connectors were located in the centre of bar fabrics, and some connectors were hooked with the intersection of bar fabrics in specimens while the others were not. The anchoring length in the inner layer panel was $75 \mathrm{~mm}$, and that in the outer layer panel was $35 \mathrm{~mm}$, the thickness of insulation layer was $50 \mathrm{~mm}$. Marks and parameters of specimens were listed in Table 1.

Table 1.Design parameter of pull-out specimens.

\begin{tabular}{cccc}
\hline Specimen & Location & $\begin{array}{c}\text { Concrete Strength } \\
\text { Grade }\end{array}$ & Amount \\
\hline PO-C-1 3 & Center of bar fabrics & C25 & 3 \\
PO-N-1 3 & Intersection & C25 & 3 \\
PO-N-4 6 & Intersection & C35 & 3 \\
\hline
\end{tabular}

\subsection{Specimen manufacturing}

To simulate the actual wall thickness, the pull-out test of the hooked connector uses specimens whose outer layer of concrete panel was $350 \mathrm{~mm} \times 350 \mathrm{~mm} \times 50 \mathrm{~mm}$ in size and inner layer was $250 \mathrm{~mm} \times$ $250 \mathrm{~mm} \times 80 \mathrm{~mm}$ in size. In order to prevent the concrete prematurely crushing, steel angles $(50 \mathrm{~mm} \times$ $50 \mathrm{~mm} \times 5 \mathrm{~mm}$ ) were welded around the outer panel as a steel frame and a formwork when concrete were poured. In order to prevent concrete splitting too early, one bar fabric layer of $8 \mathrm{~mm}$ diameter was put in 
the outer layer of concrete panel, double bar fabric layers were set in the inner panel. Each specimen used one connector.

During specimens was made, the insulation board was firstly cut into blocks $(350 \mathrm{~mm} \times$ $350 \mathrm{~mm}$ ). Secondly the blocks were slotted in the center, and connectors were inserted into the groove, ensuring that the locating ring was clamped to the insulation board. The gap was filled with foaming agent to fix the connector. Thirdly formworks of the inner panel was assembled, and double bar fabric layers were put into it according to the design location. Fourthly concrete were poured and vibrated. Before the initial setting of concrete, the insulation board was placed onto the inner panel making them located at the same planar place sixthly. Seventhly the connector was inserted into the inner panel, and the concrete of inner panel formwork was vibrated again to make the concrete compact. Eighthly, steel angle frames of the outer layer panel was placed on the insulation board, followed by placing bar fabric. And finally, pouring concrete were poured and vibrated for the outer layer panel. Design details of specimens are shown in Figure 2.
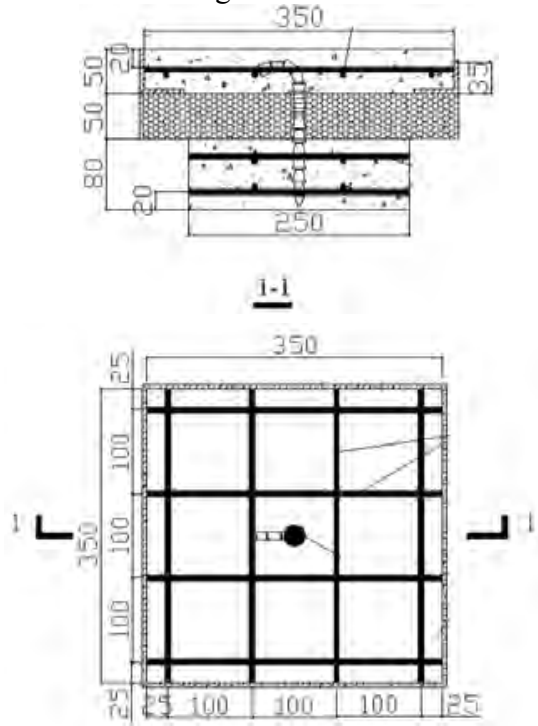

PO-C-1-3

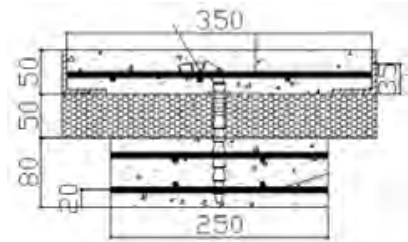

$\underline{2-2}$

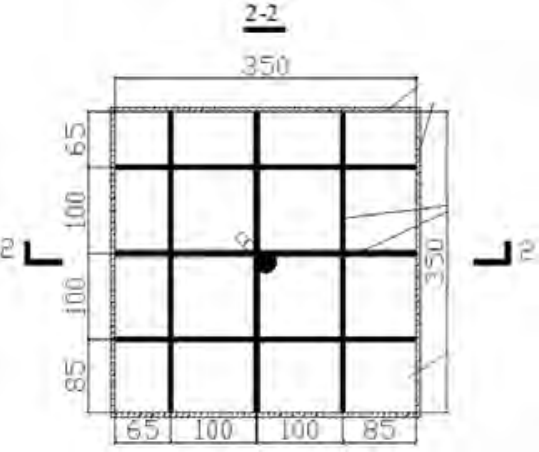

$\mathrm{PO}-\mathrm{N}-1-6$

Figure 2. Production drawing of pull-out specimens.

\subsection{Loading scheme}

The pull-out test of the connectors was carried out on a specially designed self-balanced loading device, which was monotonically loaded. Using a digital pull-out instrument manual loading, it was firstly pre-loaded, and then slowly loaded until specimen failed. Loading speed was controlled at $1 \mathrm{kN} / \mathrm{min}$. The test set-up is shown in Figure 3. 


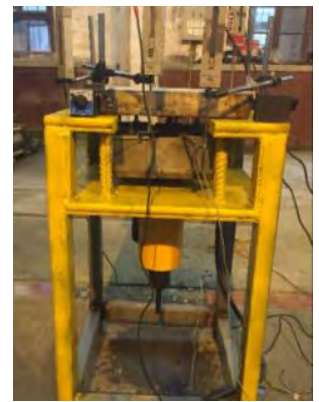

Figure 3. Pull-out loading device.

\subsection{Measuring system}

In order to simulate the worst case, the insulation layer was deducted during the test. The main measuring content includes:

(1)Strain of the hooked steel-GFRP composite connector

Both sides of the connector's surface at the insulation layer and at the inner layer of panel were measured.

(2)Slip between the connector and concrete

Displacement extensometers were installed at the upper and lower ends of connector and the surface of concrete block.

The DH3816 Data Acquisition System was used for data collection. The data points were collected and stored continuously in a computer at $1 \mathrm{~s}$ interval. The layout of measuring points is shown in Figure 4 .
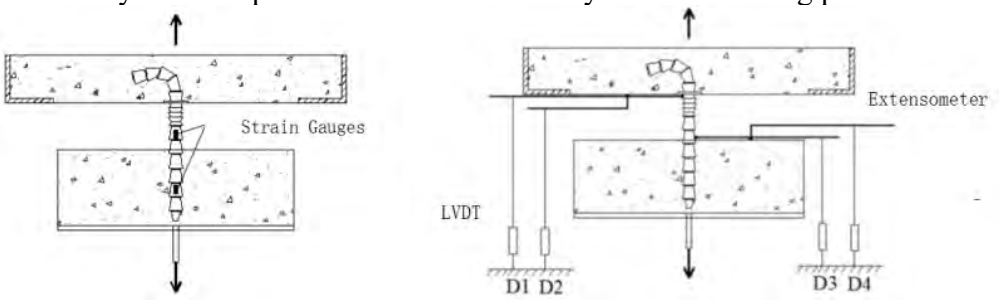

Figure 4. Lay-out of the strain gauges and displacement meters.

\section{TEST RESULTS}

\subsection{Failure modes}

When specimens of PO-C-1 3 were loaded to about $0.85 \mathrm{P}_{\mathrm{u}}\left(\mathrm{P}_{\mathrm{u}}\right.$ is the peak load), concrete surface near the upper end of the connector began to crack (split cracks), which expanded rapidly. When the load reached $\mathrm{P}_{\mathrm{u}}$, concrete near the hooks was splited off, and hook head of the connector together with the concrete were pulled out together with the concrete. The damaged concrete showed a conical shape. The specimen broke down without any damage to the connector. The lower end of the connector stayed intact. The failure modes of each specimen (PO-C-1 3) is shown in Figure 5.

When the specimens of PO-N-1 6 were loaded to about $0.9 \mathrm{P}_{\mathrm{u}}$, concrete surface near the upper end of the connector began to crack. As the load increased, the cracks extended continuously to form multiple annular fractures. When the load reached $\mathrm{P}_{\mathrm{u}}$, the outer layer concrete showed anchoring damage. The outer covering layer at the hook head broken and steel core detached from the covering layer. The elbow of steel core clasped the steel bars, thus the connector was not pulled out from the outer layer of concrete panel. The failure state of each specimen (PO-N-1 6) is shown in Figure 6. 


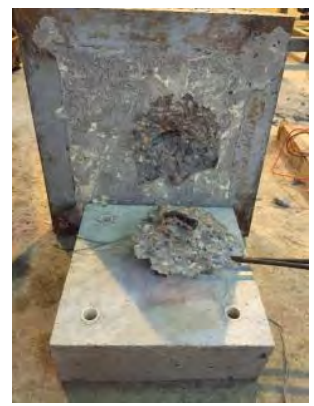

Figure 5. Failing modes of specimens PO-C-1 3.

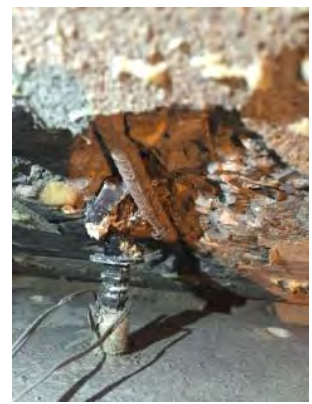

Figure 6. Failing modes of specimens PO-C-1 6.

\subsection{Load-strain curve of the connector}

The stress state of the connector is analyzed by the connectors strain changes under the pull-out loading .The relationship between the strain in the pull-out direction and the pull-out load of the hooked steel core composite connector is shown in Figure 7.

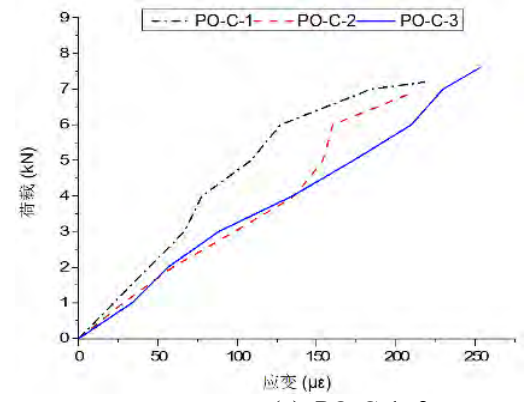

(a) $\mathrm{PO}-\mathrm{C}-1 \sim 3$

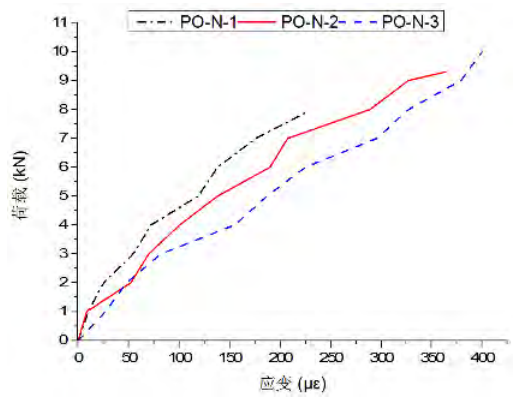

(b) $\mathrm{PO}-\mathrm{N}-1 \sim 3$

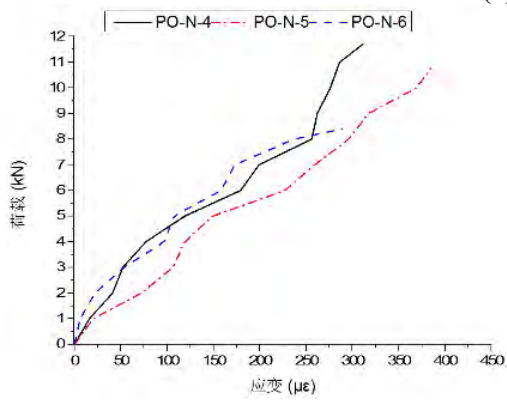

(c) PO-N-4 6

Figure 7. Load-strain curves of hook-type steel core composite connectors.

The load-strain curves of the connector show that:

(1) The positive strain of the hooked steel-GFRP composite connector in the pull-out direction was linearly related to the load. The strain of very few specimens along the pull-out direction increased slowly in the early loading stage, and the growth rate accelerated when the applied load was $0.5 \mathrm{P}_{\mathrm{u}}$.

(2) When all the test specimens were damaged, the positive strain of all connectors in the pull-out direction was smaller than the longitudinal ultimate strain of the connector, and the outer glass fiber covering layer became not broken. 


\subsection{Load-slip curve of the connector}

8.

The slippage curve of the hooked steel core composite connector the root location is shown in Figure

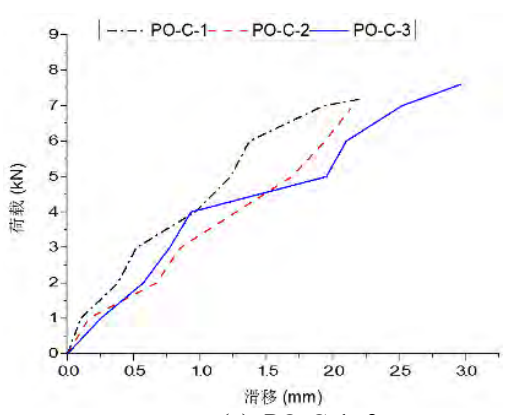

(a) $\mathrm{PO}-\mathrm{C}-1 \sim 3$

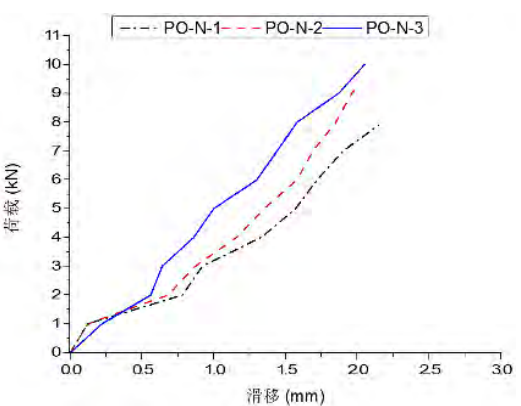

(b) $\mathrm{PO}-\mathrm{N}-1 \sim 3$

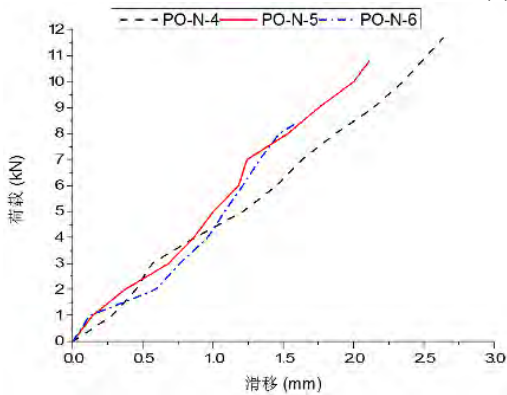

(c) $\mathrm{PO}-\mathrm{N}-4 \sim 6$

Fig.8 Load-slip curve of hook-type steel core composite connectors

The load-slip curves of the connectors show that:

(1)The peak slippages of PO-C series and PO-N series were almost the same.

(2)When the pull-out force was less than $0.1 \mathrm{P}_{\mathrm{u}}$, the slippage between the connector and concrete was less than $0.3 \mathrm{~mm}$, and the load-slip curve of the connector was basically linear. The anchoring capacity between the connector and concrete depended mainly on chemical gluing force. The slippage increased gradually as the growth of the applied load. When the load reached about $0.5 \mathrm{P}_{u}$, the chemical adhesion between the connector and concrete was almost lost. The anchoring force was mainly provided by the mechanical interaction between the inverted wedge of the connector and the concrete, and the slippage increased fast. When the load was applied to $0.85 \mathrm{P}_{\mathrm{u}} \sim 0.9 \mathrm{P}_{\mathrm{u}}$, cracks appeared at the root of the connector. When the load reached the peak value, slippage $S_{u}$ between the connector and concrete became about $1.5 \sim 3.0 \mathrm{~mm}$.

\section{ANALYSIS OF TEST RESULTS}

The test results of 9 pull-out specimens in 3 groups are shown in Table 2.

Table 2 The results of pull-out tests

\begin{tabular}{ccccc}
\hline Specimen & Location of connector & $\begin{array}{c}\text { Concrete strength } \\
\text { grade }\end{array}$ & ${\text { Peak load } \mathcal{P}_{\mathrm{u}}(\mathrm{kN})}$ & Peak slippage $S_{\mathrm{u}}(\mathrm{mm})$ \\
\hline PO-C-1 & & & 7.2 & 2.23 \\
PO-C-2 & Center of bar fabrics & $\mathrm{C} 25$ & 6.9 & 2.13 \\
PO-C-3 & & & 7.6 & 2.96 \\
\hline
\end{tabular}




\begin{tabular}{llccc}
\hline PO-N-1 & & 7.9 & 2.15 \\
PO-N-2 & Intersection & C25 & 9.3 & 2.01 \\
PO-N-3 & & 10 & 2.05 \\
\hline PO-N-4 & & 11.7 & 2.64 \\
PO-N-5 & Intersection & \multirow{2}{*}{ C35 } & 10.8 & 2.11 \\
PO-N-6 & & & 8.4 & 1.59 \\
\hline
\end{tabular}

\subsection{Impact of the location of connector}

From Table 2, it can be shown that:

When concrete strength grade was the same and the hook head of the connector is located at the center of the bar fabrics without connecting the steel bar, the average peak pull-out load of the specimens PO-C-1 3 was $7.23 \mathrm{kN}$. The value was lower than that $(9.1 \mathrm{kN})$ of the specimens PO-N-1 3, of which the hook head located at the intersection of the bar fabric layer. It indicated that the hook head of the connector connecting the bar fabric layer could increase the pull-out capacity.

\subsection{Impact of concrete strength grade}

The concrete strength grades of PO-N-2 3 and PO-N-4 5 were C25 and C35, respectively, and the other parameters and structures were the same. It can be known that: when the other conditions were the same, the higher the concrete strength grade, the higher the pull-out capacity of the connector was, and the capacity of the specimen with C35 concrete was $16.1 \%$ higher than that of the C25 specimen. When the concrete strength grade was increased, the slippage between the connector and concrete reduced. The concrete strength grade had no significant effect on the peak slippage between the connector and concrete.

\subsection{Safety evaluation}

Sandwich walls belong to the outer enclosure components, Load Code for the Design of Building Structures (GB50009-2012) can be referred to for calculating loads. For a project in Nanjing, the pull-out capacity of prefabricated sandwich wall can be calculated by the method in Codes and compared with the average value of test results, as shown in Table 3.

Table 3 The comparison of design and test pull-out load

\begin{tabular}{ccccc}
\hline Specimen & $\begin{array}{c}\text { Concrete strength } \\
\text { grade }\end{array}$ & $\begin{array}{c}\text { Average value of } \\
\text { test results/kN }\end{array}$ & Design value/kN & Safety coefficient \\
\hline PO-C-1 3 & C25 & 7.23 & 1.22 & 5.93 \\
PO-N-1 3 & C25 & 9.1 & 1.22 & 7.46 \\
PO-N-4 6 & C35 & 10.3 & 1.22 & 8.44 \\
\hline
\end{tabular}

It can be seen from the data in Table 3 that all of the test results of the pull-out load were more than 5 times of the design value, which can satisfy the engineering design requirements and have sufficient safety reserve.

\section{CONCLUSION}

In this paper, nine new hooked steel-GFRP composite connector specimens were carried out and test results were analysed.

(1) All the pull-out specimens failed with cone anchoring damage of concrete in the outer layer panel. When the connector was not connected with the bar fabrics, the connector was pulled out without any damage in outer fiber. If connected with the bar fabrics, the outer covering fiber of the hook fractured without any sliding of the steel core, and the outer layer of panel did not fall. Thus, it can be guaranteed in the real applications that outer layer panels do not fall off after damage. 
(2) Connection between hook head of the connector and the bar fabric layer can increase the pull-out capacity significantly.

(3) When the other conditions are the same, the higher the concrete strength grade, the greater the pull-out capacity of the connector is. The concrete strength grade has no significant effect on the peak slippage between the connector and concrete.

(4) The pull-out performance of the hooked steel core composite connector satisfies the engineering design requirements with adequate safety reserve.

\section{ACKNOWLEDGEMENT}

The author gratefully acknowledge financial support from National Key R\&D Program of China (2016YFC0701703), National Natural Science Foundation of China (51678136) and the Fundamental Research Funds for the Central Universities.

\section{REFERENCES}

[1] JIANG Wei-qing,ZHANG Yun,QING Heng, "Tensile Tests of New Type of FRP Connectors for Precast Concrete Sandwich Walls",Journal of Industrial Construction,43:161 163,2013.

[2] YANG Jia-lin, XUE Wei-chen, "State-of-the-art of Fiber Reinforced Plastic Connectors in Precast Concrete Sandwich Wall Panels", Journal of Low Temperature Architecture Technology, 8:139 141,2012.

[3] GU Ming-wang, "Thoughts on the Design of Sandwich Walls at home and abroad", Journal of Housing \& Real Estate, 12:53 59,2015.

[4] WAN Chao-yang, CHEN Guo-xin, "The Research Status of Insulated Connector in Precast Thermal insulation wall Panels",Fiber Reinforced Plastics/Composites, 11:81 84,2015.

[5] National Standard of the People's Republic of China, "Load Code for the Design of Building Structures (GB50009-2012)”, Beijing: China Architecture \& Building Press, 2012.

[6] National Standard of the People's Republic of China, "Technical Code for Metal and Stone Curtain Wall Engineering(JBJ133-2013)”,Beijing: China Architecture \& Building Press, 2013. 